\title{
Death by twins: a remarkable case of dystocic childbirth in Early Neolithic Siberia
}

\author{
Angela R. Lieverse ${ }^{1}$, Vladimir Ivanovich Bazaliiskii ${ }^{2} \&$ \\ Andrzej W. Weber ${ }^{3}$
}

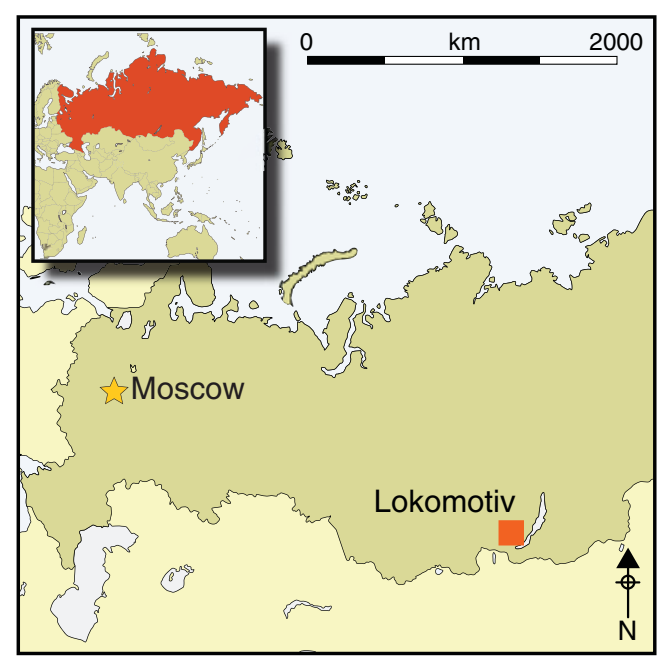

Death during childbirth was a significant risk for women in prehistoric and pre-modern societies, but it has rarely been documented by archaeology. The evidence for twins in the archaeological record has likewise been largely circumstantial, with few confirmed cases. Maternal mortality in childbirth is often obscured by the special ritual practices associated with this type of death. In the case of twin births that difficulty is compounded by past social attitudes to twins. The earliest confirmed evidence for obstructed labour comes from the burial of a young woman who died attempting to deliver twins in the middle Holocene hunter-gatherer cemetery at Lokomotiv in southern Siberia some 7000 to 8000 years ago.

Keywords: Baikal, Early Neolithic, twins, breech birth, pregnancy, parturition, obstructed labour

\section{Introduction}

Despite the high mortality that must have been associated with pregnancy and parturition (giving birth) in the past (e.g. Högberg et al. 1987; Arriaza et al. 1988; Slaus 2000), cases of fatal dystocia (obstructed childbirth) are uncommon in the archaeological record, particularly in the absence of preserved soft tissue. Indeed, since the 1970s, only about 20 cases of pregnant or labouring females (i.e. interred with fetal remains in situ) have

1 Department of Archaeology and Anthropology, University of Saskatchewan, Saskatoon, SK, S7N 5B1, Canada (Email: angela.lieverse@usask.ca)

2 Department of Archaeology and Ethnography, Irkutsk State University, Irkutsk 664003, Russia (Email: bazalirk@yandex.ru)

3 Department of Anthropology, University of Alberta, Edmonton, AB, T6G 2H4, Canada (Email: andrzej.weber@ualberta.ca) 
been published in the archaeological literature, the vast majority appearing to represent complications due to childbirth (e.g. Sjovold et al. 1974; Hawkes \& Wells 1975; Wells 1978; Owsley \& Bradtmiller 1983; Pounder et al. 1983; Persson \& Persson 1984; Högberg et al. 1987; Malgosa et al. 2004; Rascón Pérez et al. 2007; Cruz \& Codinha 2010; Willis \& Oxenham 2013). The explanation for this apparent contradiction-high maternal and fetal mortality in antiquity but little direct evidence for it - may lie largely in the fact that both the mother and child must have died together, the former being buried with her unborn (or partially born) fetus in utero, in order for the event to be archaeologically visible. In fact, one study of pre-Columbian female mummies from Chile found that not only did 14 per cent of those of child-bearing age die from complications associated with parturition, but of those, only 17 per cent (or 3 out of 18) failed to deliver their infants completely (Arriaza et al. 1988). This archaeological 'invisibility', compounded by possible cultural practices to remove fetal remains from the bodies of their deceased mothers (e.g. the Roman Empire's Lex Caesarea), potential (albeit rare) cases of 'coffin birth' (e.g. Schulz et al. 2005; Rascón Pérez et al. 2007; Lasso et al. 2009), and the myriad taphonomic factors differentially affecting the preservation of delicate infant and fetal remains (Guy et al. 1997), can account for the rarity of pregnant and labouring females recovered from archaeological contexts.

In a similar vein, although human twins were undoubtedly present in the past, just as they are today, confirmed evidence of them is exceptionally infrequent. Most archaeologically documented twins (e.g. Black 1967; Chamberlain 2001; Einwögerer et al. 2006; Crespo et al. 2011; Halcrow et al. 2012; Flohr 2014) represent possible or probable cases, with twin status being inferred from circumstantial evidence such as physical similarities of the remains themselves or peculiarities of their burial context. In fact, several presumed cases of ancient twins have been subsequently disproved (Hawass \& Saleem 2011; Marshall et al. 2011). Only very rarely can twin status actually be confirmed by irrefutable evidence, such as the discovery of dual sets of fetal remains in utero (e.g. Owsley \& Bradtmiller 1983).

Here we present not only one of the oldest archaeologically documented cases of dystocic death, but also the earliest confirmed set of human twins in the world. The remains are those of a young adult female from the middle Holocene Cis-Baikal cemetery of Lokomotiv (Siberia, Russian Federation), found with the partial skeletons of two full-term fetuses located in her pelvic area and between her thighs. Radiocarbon dates obtained from both the mother and infants place the remains firmly within the Early Neolithic period (8000$7000 / 6800 \mathrm{cal}$ BP; Weber et al. 2006). All three individuals appear to have died together from complications associated with childbirth.

\section{Materials and methods}

Lokomotiv is a middle Holocene hunter-gatherer cemetery located in the Cis-Baikal, the vast mountainous region north and west of Lake Baikal in south-eastern Siberia. The cemetery is situated on the west bank of the Angara River, at its confluence with the Irkut (Bazaliiskii 2010); today, it is located within the modern city of Irkutsk (Figure 1). Due to its present urban setting, Lokomotiv has yet to be completely excavated. However, a considerable portion of it - that situated within a large municipal park-was excavated between 1980 and 1997. During this period, 59 graves, representing 101 individuals (including the

(C) Antiquity Publications Ltd, 2015 
subjects of this paper), were recovered (Bazaliiskiy \& Savelyev 2003; Bazaliiskii 2010). The Lokomotiv burials represent the Cis-Baikal's Early Neolithic (EN) occupation, dating to 8000-7000/6800 cal BP (Weber et al. 2006; Bazaliiskii 2010). It must be stressed that, while in the West the term 'Neolithic' implies sedentism and agriculture, in Siberian archaeology it is characterised by the introduction of pottery, and ground-stone and bow and arrow technology. Indeed, the EN and other middle Holocene inhabitants of the Cis-Baikal were, in every sense of the word, mobile foragers subsisting predominantly on game hunting, fishing and sealing (Weber et al. 2002, 2011).

Grave R11 was excavated from the southern portion of the Lokomotiv cemetery, referred to as Raisovet, in 1997. It represents a primary interment, as indicated by the anatomical positioning and articulation of the main burial. The main individual, LOR 11.1, was a relatively complete and well-preserved skeleton in an extended and supine position. The body was orientated with the cranium towards the east (towards the bank of the Angara River) (Figures $2 \& 3$ ). Grave accompaniments were represented exclusively by fifteen (decorative) marmot teeth: three on the right side of the cranium, seven among the ribs (mostly on the right side), and five just inferior to the lower right ribs (Figures $2 \& 3$ ). The burial was not unique or unusual in any way, with its location (within the cemetery), body positioning, orientation and grave goods all typical of EN interments in the region, and of Lokomotiv in particular. Marmot teeth were common grave goods, being found in male, female and sub-adult graves, and probably represented decorative accessories affixed to garments. LOR 11.1 was directly radiocarbon dated to 7725-7630 cal BP (TO-10189: $6750 \pm 70 \mathrm{BP}$ ), placing it in the early part of the EN (Weber et al. 2006).

LOR 11.1 was represented by all major limb bones and most manual, pedal, cranial, costal and vertebral elements. While some bones, particularly those of the thorax and superior cranial vault, were quite fragmented, skeletal preservation was generally good. A complete set of maxillary and mandibular dentition was also recovered, fully formed and erupted, with moderate dental wear (i.e. stages 4-5 using the Smith [1984] method). A conservative age at death estimate of 20-25 years was based on the iliac auricular surface and epiphyseal fusion (Moorrees et al. 1963; Powell \& Brodie 1963; Webb \& Suchey 1985; Meindl \& Lovejoy 1989; Albert \& Maples 1995). The sex was clearly indicated as female by non-metric cranial and pelvic indicators (as outlined by Buikstra \& Ubelaker 1994: 16-21). Other than a small carious lesion on the right mandibular first molar, no skeletal or dental pathological conditions were observed.

In addition to the main individual described above, fetal remains were also recovered from grave R11. These were restricted to the abdominal and pelvic region of the female's skeleton, as well as to the area between her thighs (Figures $2 \& 3$ ). It is important to note that only postcranial fetal remains, specifically fragmented long bones and vertebral arch fragments, were situated outside of the uterine area (i.e. between the femora of LOR 11.1). Furthermore, while other postcranial fetal bones (fragmented long bones, ribs, vertebral arches and coxal fragments) were located in the abdominal area of the main skeleton, all cranial fetal remains (including a left mandibular corpus and a partially formed deciduous tooth crown) were limited to the pelvis (i.e. located on the left and right ossa coxae and the sacrum; see Figure 3). A sample of fetal bone fragments was directly radiocarbon dated to 


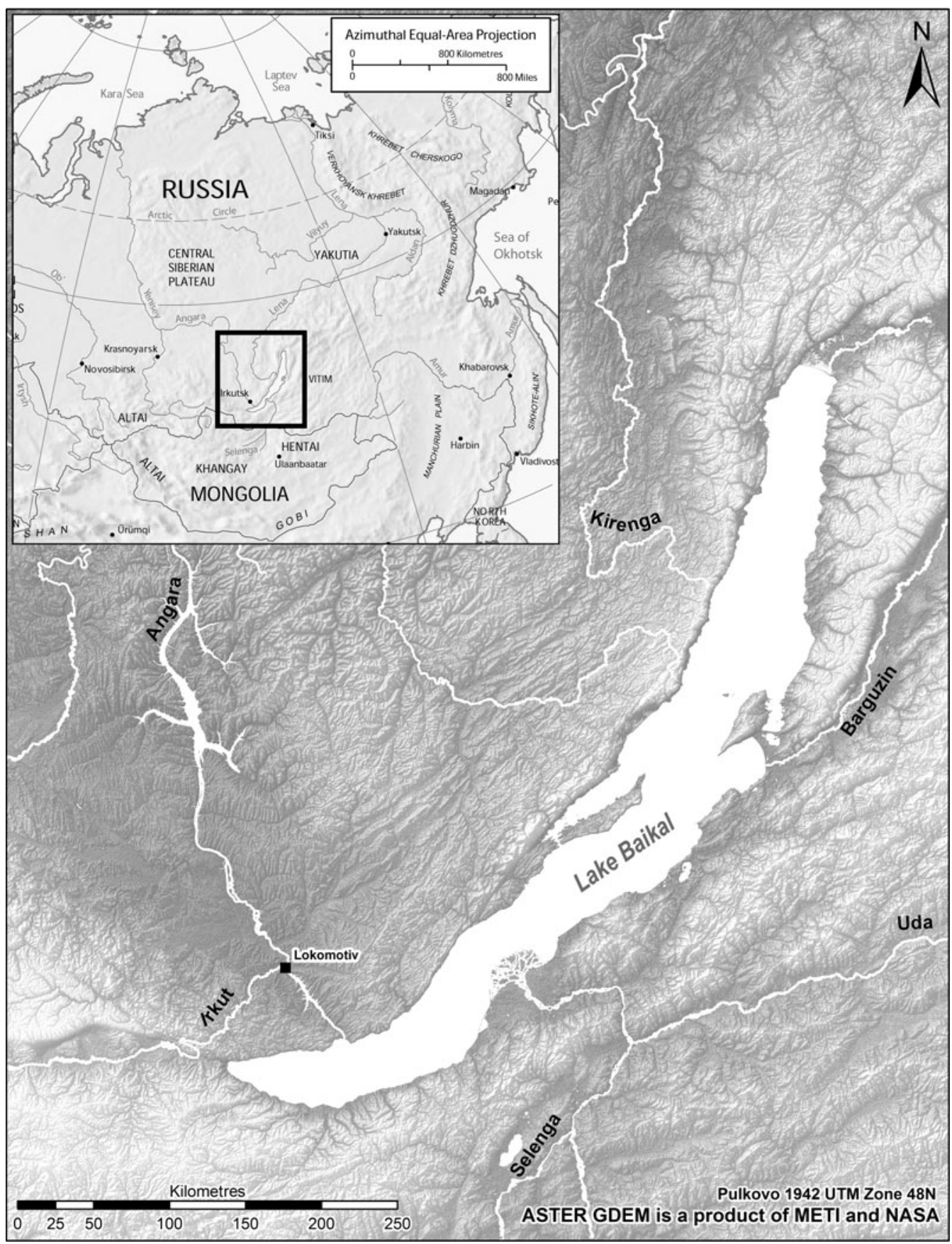

Figure 1. Map of Cis-Baikal, showing the location of the Lokomotiv cemetery.

(C) Antiquity Publications Ltd, 2015 
7810-7640 cal BP (TO-10190: 6829士100 BP; Weber et al. 2006), making them consistent with the maternal date.

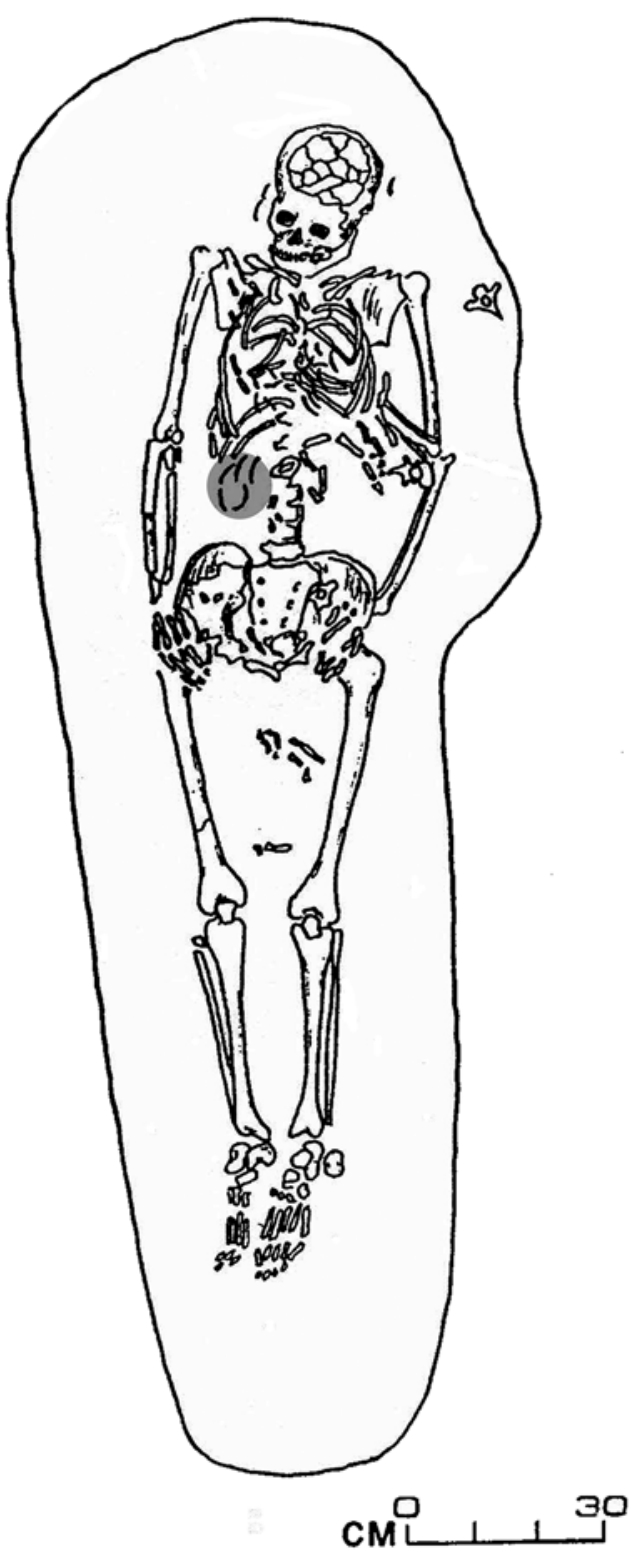

Figure 2. Plan drawing of Lokomotiv, grave R11. The positioning and completeness of the main burial (LOR 11.1) is clearly visible, as are the fetal remains within the lower abdominal/pelvic region and between the thighs. The grey ellipse on the right side of the lower vertebral column indicates five marmot teeth (grave accompaniments), not fetal elements.
The grave R11 fetal remains were photographed, collected and labelled by the excavators in 1997, but they were not examined by a biological anthropologist (Angela Lieverse) until 15 years later. In 2012, a clear duplication of cranial elements was documented, indicating the presence of two distinct individuals, LOR 11.2 and LOR 11.3 (Figure 4). Four different cranial elements-the pars basilaris and left pars lateralis of the occipital bone (Figure 5), the pars petrosa of the left temporal bone (Figure 6) and the post-sphenoid (Figure 7)-were duplicated. Several of these elements and their contralateral partners were preserved well enough for metric analyses (Table 1). Other duplicated cranial elements (e.g. the post-sphenoids) could not be measured due to fragmentation and post-mortem damage. While the representation of fetal postcranial bones and additional cranial fragments was not inconsistent with two individuals, other than the humerus (with three unsided humeral diaphyses being documented), the generally poor condition of these remains did not allow duplication among them to be conclusively demonstrated, nor for additional measurements to be taken (Table 2).

\section{Results and discussion}

\section{Confirmed twins}

Both identifiable sets of fetal remains were recovered in situ with the skeleton of their labouring mother and represented similar stages of development. Fetal cranial measurements (Table 1) were consistent with one another and characteristic of near or full-term fetuses, with ages at death

(C) Antiquity Publications Ltd, 2015 


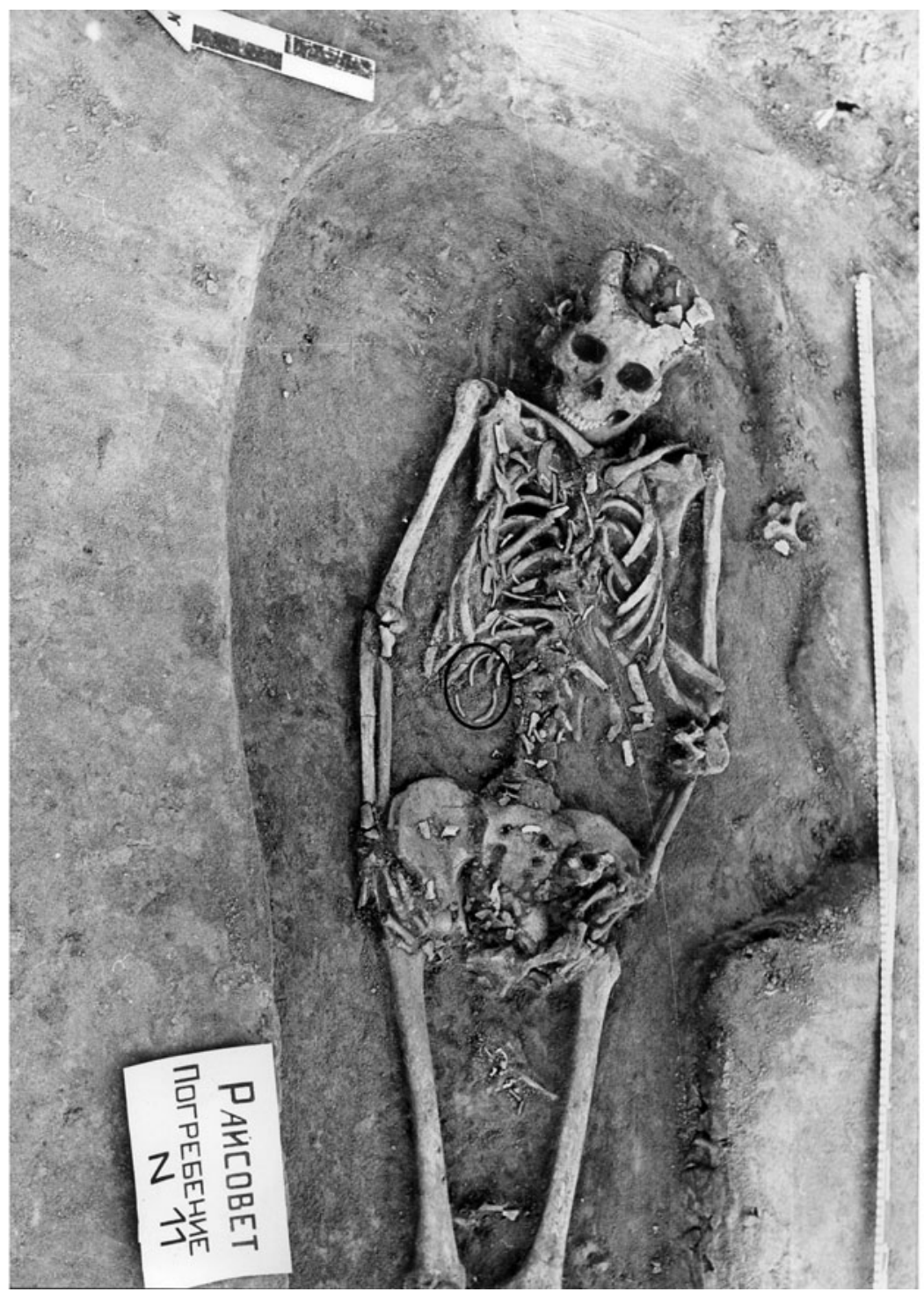

Figure 3. In situ photograph of Lokomotiv, grave R11. Postcranial fetal remains are situated within the lower abdominallpelvic region and between the left and right femora of the main burial (LOR 11.1), while cranial fetal remains are restricted to the inferior pelvic region. Note that the ellipse on the right side of the lower vertebral column encircles five marmot teeth (grave accompaniments), not fetal elements.

ranging largely between 36 and 40 prenatal weeks (Fazekas \& Kósa 1978; Scheuer \& MacLaughlin-Black 1994; Schaefer et al. 2009: 11-23). One measurement (maximum width of the left pars petrosa of Fetus 2 [LOR 11.3]) was smaller than typical for a 36-week fetus but, given the fact that twins are often smaller than single infants, particularly after 36 weeks gestation (Ghai \& Vidyasagar 1988; Luke et al. 1991), this was not unexpected or contradictory. In addition to confirming similar developmental stages, measurements

(C) Antiquity Publications Ltd, 2015 


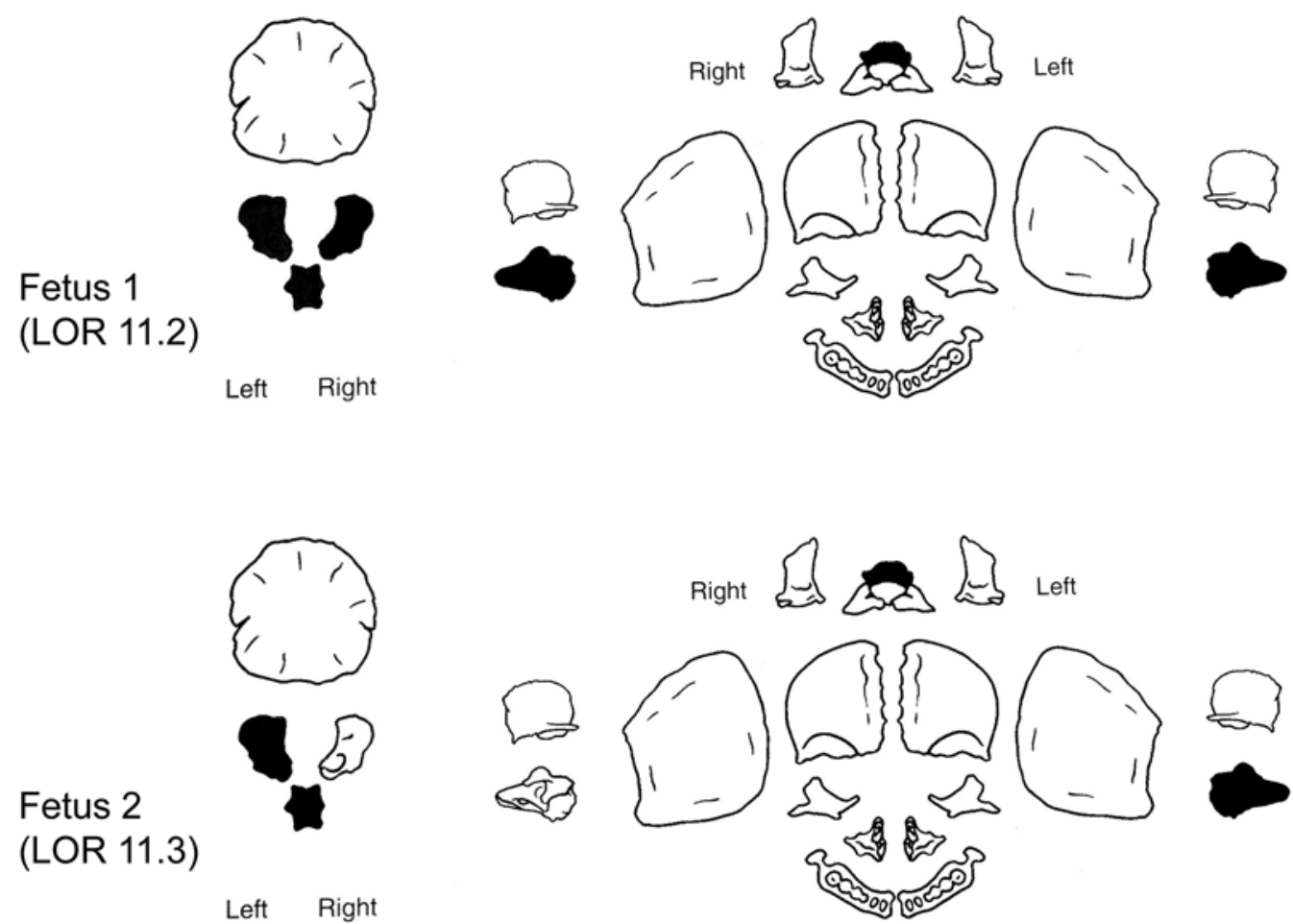

Figure 4. Diagram of identified and duplicated fetal cranial bones. Fetus 1 (LOR 11.2) is represented by the left and right partes lateralis and pars basilaris of the occipital bone, the left and right partes petrosa of the temporal bones, and the post-sphenoid of the sphenoid bone (top). Fetus 2 (LOR 11.3) is represented by the left pars lateralis and pars basilaris of the occipital bone, the left pars petrosa of the temporal bone, and the post-sphenoid of the sphenoid bone (bottom). Image modified from Schaefer et al. 2009: 397 (reproduced with permission from Elsevier).

revealed a slight size discrepancy between the two fetuses, with one being larger than the other (Table 1). These differences - calculated for each dimension by subtracting the smaller value from the larger one and dividing the difference by the larger value (as per Miller $e$ t al. 2012) — ranged from 0.91 per cent (sagittal length of the pars basilaris) to 12.87 per cent (maximum width of the pars basilaris). Size discrepancies are not atypical in twins and, if less than 18 per cent (estimated birth weight), are not considered to be abnormal or detrimental (Blickstein \& Kalish 2003; Breathnach et al. 2011). All evidence, therefore, indicated that the fetal remains were consistent with near or full-term twins.

Although human twins are relatively uncommon, representing 1-3 per cent of births today, their frequencies have varied over time and geographically across various populations (Ball \& Hill 1996; Tough et al. 2000; Chauhan et al. 2010). In recent years, for example, multiple births have increased considerably, reflecting, at least in part, advances in modern reproductive assistance (Tough et al. 2000; Chauhan et al. 2010). Several potential cases of twin death have been identified from the archaeological record in the last decade, contributing immensely to our understanding of past perspectives on multiple births, personhood, death and mortuary practice (e.g. Einwögerer et al. 2006; Crespo et al. 2011; Halcrow et al. 2012; Flohr 2014). While most provide compelling arguments in support 


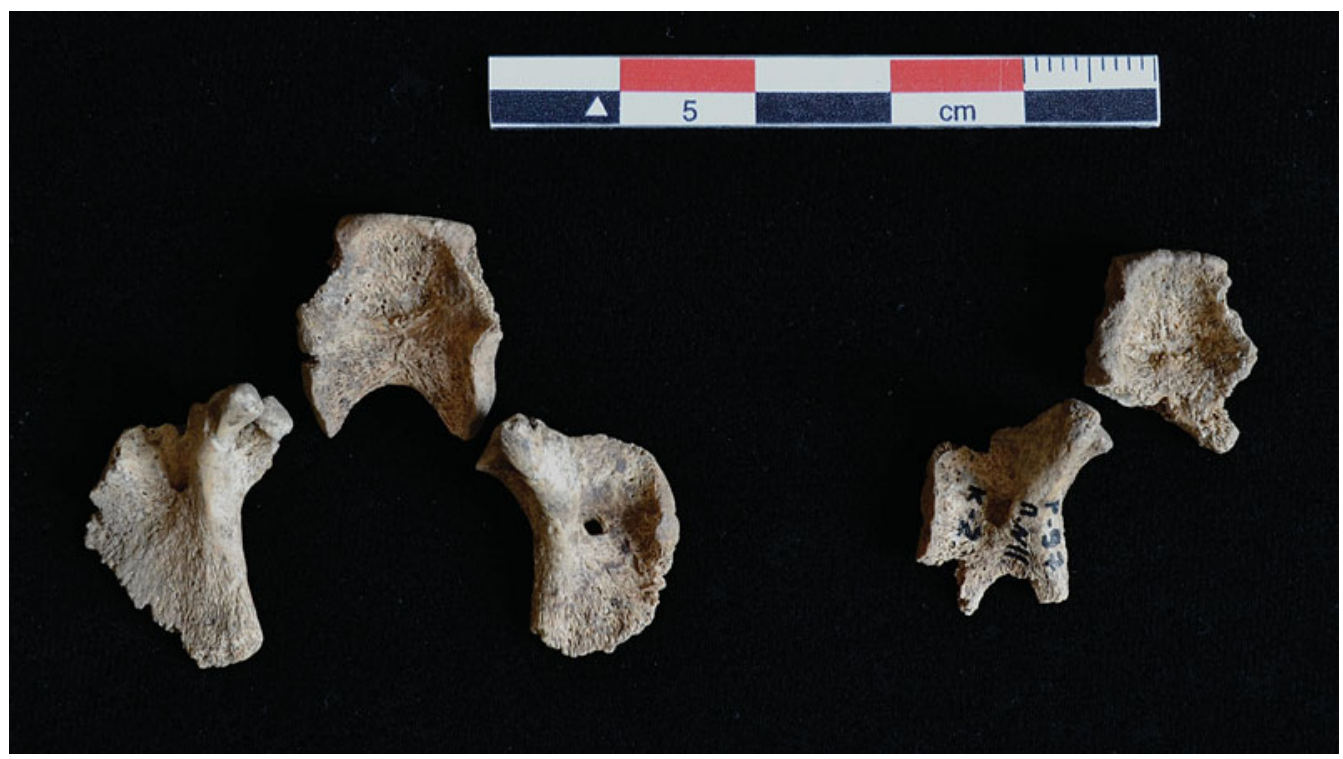

Figure 5. Left) superior view of left and right partes lateralis and pars basilaris (occipital bone) of Fetus 1 (LOR11.2); right) left pars lateralis and pars basiliars (occipital bone) of Fetus 2 (LOR 11.3).

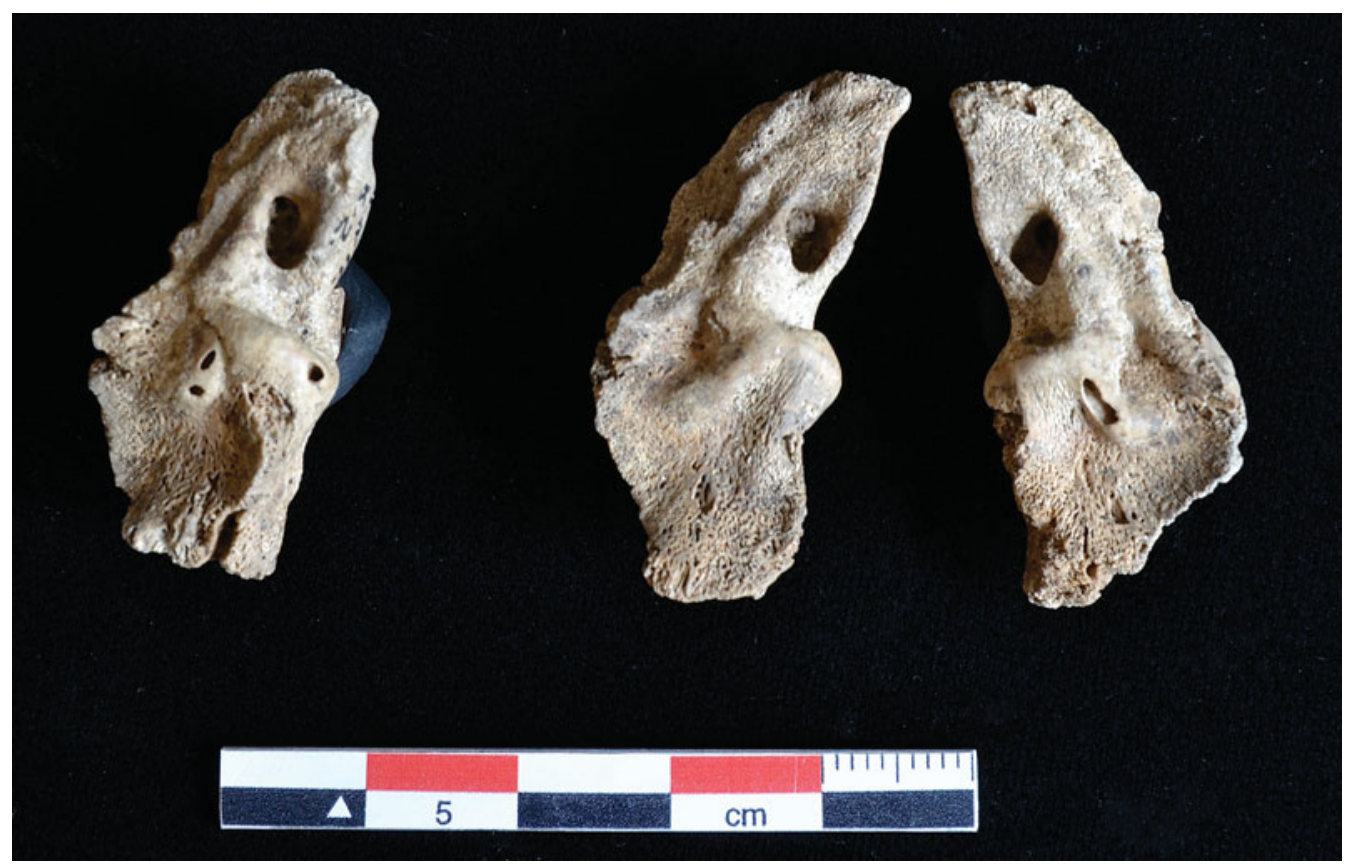

Figure 6. Left) superior view of left pars petrosa (temporal bone) of Fetus 2 (LOR 11.3); middle and right) left and right partes petrosa (temporal bones) of Fetus 1 (LOR 11.2).

(C) Antiquity Publications Ltd, 2015 


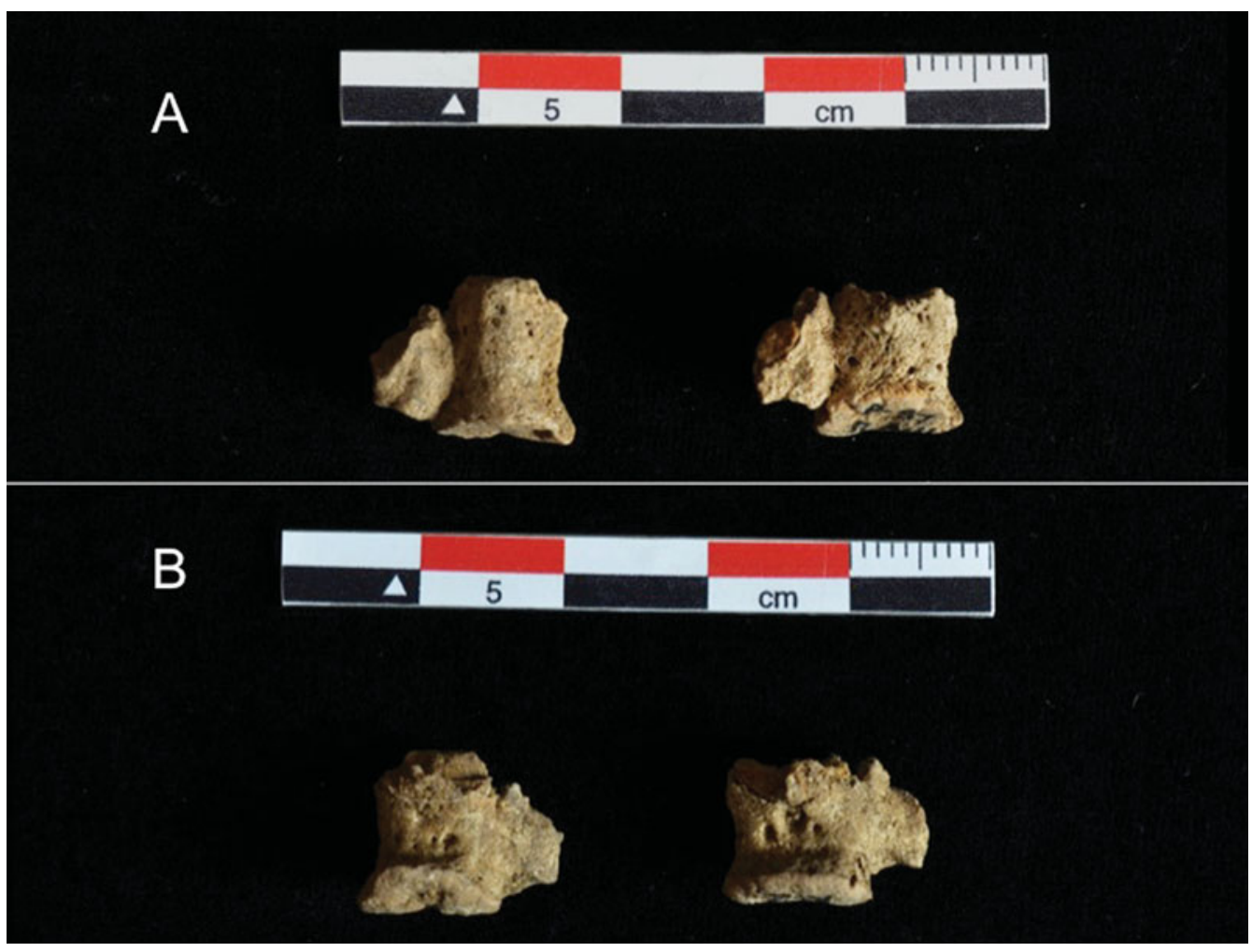

Figure 7. A) inferior; and B) superior views of the post-sphenoid elements (sphenoid bones) of Fetus 2 (LOR 11.3) (left) and Fetus 1 (LOR 11.2) (right).

of twin status, all ultimately rely on circumstantial evidence such as contemporaneous interment of two infants coupled with similar ages at death, matching skeletal or dental traits, or peculiarities of mortuary ritual (e.g. unique body positioning and unusual types or amounts of grave goods). The fact remains that however common (or uncommon) human twins might have been in the past, they are virtually impossible to confirm from most archaeological contexts.

Only under the most unusual of circumstances — such as both infants being interred together in utero, as is the case here-can we be absolutely certain that twins are represented. Based on these stringent criteria, only one other case of confirmed human twins has been reported in the archaeological literature, from an historic or ancestral Arikara (1600-1832 AD) burial from South Dakota, USA (Owsley \& Bradtmiller 1983). In that case, duplicated fetal remains, aged about 24 weeks gestation, were recovered from the pelvic and abdominal area of an adult female skeleton; death did not appear to have resulted from complications associated with (premature) childbirth (Owsley \& Bradtmiller 1983). With radiocarbon dates of approximately 7810-7640 cal BP, therefore, the case from Lokomotiv represents the earliest confirmed set of human twins worldwide. It is also unique in the Cis-Baikal among 431 other middle Holocene human skeletons (291 adult and 140 sub-adult) documented by the present authors. 
Table 1. Duplicated fetal cranial elements recovered.

\begin{tabular}{|c|c|c|c|c|c|c|c|c|}
\hline Element & Portion & Side & MW & Age & ML & Age & SL & Age \\
\hline \multicolumn{9}{|c|}{ Fetus 1 (Burial LOR 11.2) } \\
\hline Occipital & pars lateralis & left & 15.75 & 40 & 21.95 & $36-40$ & $\mathrm{n} / \mathrm{a}$ & $\mathrm{n} / \mathrm{a}$ \\
\hline Occipital & pars lateralis & right & 14.98 & 40 & * & * & $\mathrm{n} / \mathrm{a}$ & $\mathrm{n} / \mathrm{a}$ \\
\hline Occipital & pars basilaris & $\mathrm{n} / \mathrm{a}$ & 14.53 & 40 & 16.28 & 40 & 12.15 & $38-40$ \\
\hline Temporal & pars petrosa & left & 16.01 & $36-38$ & 35.10 & 38 & $\mathrm{n} / \mathrm{a}$ & $\mathrm{n} / \mathrm{a}$ \\
\hline Temporal & pars petrosa & right & 15.75 & $36-38$ & 34.01 & $36-38$ & $\mathrm{n} / \mathrm{a}$ & $\mathrm{n} / \mathrm{a}$ \\
\hline Sphenoid & post-sphenoid & $\mathrm{n} / \mathrm{a}$ & $*$ & * & $*$ & $*$ & $\mathrm{n} / \mathrm{a}$ & $\mathrm{n} / \mathrm{a}$ \\
\hline \multicolumn{9}{|c|}{ Fetus 2 (Burial LOR 11.3) } \\
\hline Occipital & pars lateralis & left & * & * & * & $*$ & $\mathrm{n} / \mathrm{a}$ & $\mathrm{n} / \mathrm{a}$ \\
\hline Occipital & pars lateralis & right & not recovered & & & & & \\
\hline Occipital & pars basilaris & $\mathrm{n} / \mathrm{a}$ & 12.66 & $36-38$ & * & $*$ & 12.04 & $36-38$ \\
\hline Temporal & pars petrosa & left & 14.73 & 34 & 31.92 & $34-36$ & $\mathrm{n} / \mathrm{a}$ & $\mathrm{n} / \mathrm{a}$ \\
\hline Temporal & pars petrosa & right & not recovered & & & & & \\
\hline Sphenoid & post-sphenoid & $\mathrm{n} / \mathrm{a}$ & $*$ & * & $*$ & * & $\mathrm{n} / \mathrm{a}$ & $\mathrm{n} / \mathrm{a}$ \\
\hline
\end{tabular}

Notes: MW: maximum width (in mm), after Schaefer et al. 2009: 9, 21

ML: maximum length (in mm), after Schaefer et al. 2009: 9, 21

SL: sagittal length (in mm), after Schaefer et al. 2009: 9

Age: estimated age in fetal weeks, after Fazekas \& Kósa 1978

n/a: not applicable

* no data (measurements could not be taken due to post-mortem damage)

Table 2. Other fetal remains recovered (LOR 11.2 and/or LOR 11.3).

\begin{tabular}{llc}
\hline Element & Portion & Quantity \\
\hline Mandible & left corpus & 1 \\
Deciduous molar & partially formed crown & 1 \\
Humerus & diaphysis & 3 \\
Ulna & diaphysis & 2 \\
Tibia & diaphysis & 2 \\
Long bone & diaphyseal fragment & 7 \\
Os coxae & ilium fragment & 2 \\
Os coxae & ischium fragment & 1 \\
Cranium & cranial vault fragment & 16 \\
Vertebra & vertebral arch fragment & 8 \\
Costae & shaft fragment & 11 \\
\hline
\end{tabular}

What is interesting to consider for both the Baikal and South Dakota cases is that, while twins have been posthumously confirmed, their identity was unlikely to have ever been known to their mothers and community members because they were never born. In fact, the typical EN burial treatment extended to LOR 11.1—whose grave was typical in every way for the region and time period (see above) — may suggest not only that the uniqueness of her twin pregnancy was unknown, but also that death during childbirth (see below) was not particularly unusual at the time. Due to this possible twin anonymity, therefore, it is difficult to use this case to interpret perceptions of multiples, or the significance of the mortuary practices ascribed to them, in the Cis-Baikal's middle Holocene.

C) Antiquity Publications Ltd, 2015 


\section{Fatal dystocia}

The relative locations of the fetal remains, and their near- or full-term development, strongly suggest an incomplete breech (feet- or bottom-first) birth of the first infant and a normal vertex (head-down) presentation of the second. Even considering fragmentation and possible post-mortem shifting of skeletal elements, it is clear that only post-cranial fetal bones were recovered from outside of the uterine area (i.e. between the mother's femora), and that all fetal cranial elements were located together, low in the maternal pelvis (Figures $2 \& 3$ ). It is also likely, if not certain, that the breech infant was partially delivered at the time of death rather than being expelled by gases created during decomposition, a process referred to as post-mortem fetal extrusion or 'coffin birth'. Although rare, post-mortem fetal extrusion has been documented in both the forensic pathological (Schulz et al. 2005; Lasso et al. 2009) and archaeological (Rascón Pérez et al. 2007) literature, with the condition appearing to affect only pre-term (and thus relatively small) vertex-presenting fetuses (Schulz et al. 2005). In fact, of the three recent cases reported in the literature, fetal age ranged from 28 to 32 weeks gestation (Schulz et al. 2005; Rascón Pérez et al. 2007, Lasso et al. 2009), which is considerably less mature than the grave R11 twins. Both positioning and near- or full-term fetal development, then, make it exceedingly unlikely that the first twin was expelled via post-mortem fetal extrusion. Rather, death appears to have occurred during the birth process, but before either infant could be completely delivered. Perhaps even more telling is the fact that the partially birthed breech fetus was interred in situ, between its mother's thighs, indicating that it was not (or could not be) removed from the mother's body, even with the muscle laxity that accompanies death.

The presence of twins, and the breech presentation of the first twin, in particular, appear to have caused an obstructed labour- "a failure to progress due to mechanical problems" (Neilson et al. 2003: 192) —and to have contributed to the death of all three individuals. It is worth noting that of the three pre-Columbian female mummies mentioned above, who had failed to completely deliver their infants (Arriaza et al. 1988), one had died while birthing probable twins and another while delivering a breech singleton; both conditions appear to increase the already high risk of death during childbirth (see below). Among twin births, malpresentation (breech or transverse) of one or both fetuses is relatively common, occurring approximately 60 per cent of the time, but it is much more likely for the first twin to be vertex than for it to be breech (Chervenak et al. 1985; DeVeciana et al. 1995; Boggess \& Chisholm 1997). Only about 20 per cent of modern twin deliveries are breech/vertex, in which the first infant is breech and the second vertex, as appears to be the case here, and these are generally considered to be high risk (Chervenak et al. 1985; Laros \& Dattel 1998).

Perinatal and maternal mortality is relatively high for breech births under the best of circumstances, even among singletons today (e.g. see Hannah et al. 2000), but this is compounded in twin deliveries, especially breech/vertex ones. One complicating factor is the uncommon but extremely dangerous condition of interlocking twins, in which breech/vertex fetuses become locked, chin on chin, during vaginal delivery (Nissen 1958; Kurzel 1998). While very rare, occurring in less than 0.15 per cent of twin births, fetal mortality associated with interlocking is estimated at between 30 and 50 per cent if a Caesarean section is not performed (Cohen et al. 1965; Kahunda 1972; Rydhstrom \& Cullberg 1990; Kurzel 1998; 
Nassar et al. 2004; Carroll \& Yeomans 2006; Borah \& Das 2012). If the first infant is partially delivered, as appears to have been the case here, manual manipulation such as the Kimball-Rand manoeuvre (Kimball \& Rand 1950) may allow for vaginal delivery, but with a high risk of maternal tissue damage (Bowman 1983). In fact, in many modern cases, interlocked twins can only be delivered vaginally if the cranium of the first (deceased) infant is perforated and/or removed, and the birth of the second infant is assisted with forceps (Gordon 1956; Bowman 1983; Kurzel 1998).

Another risk factor for breech deliveries, whether for twins or singletons, is head entrapment, the failure of the infant's cranium to negotiate the birth canal following its body. The occurrence of entrapment among breech births today is in the range of 5.6-9.3 per cent, being somewhat more frequent among pre-term fetuses because of the larger size of their heads compared with their bodies (Van Eyk \& Huisjes 1983; Anderson \& Strong 1988; Robertson et al. 1995; Tunde-Byass \& Hannah 2003). Whether the ultimate mechanism behind entrapment stems from the infant (e.g. deflexed cranium, hydrocephaly) or mother (e.g. contracted lower uterus, incompletely dilated cervix, pelvic tumours), fetal death can occur quite quickly due to compression of the umbilical cord (i.e. asphyxia) or trauma to the neural tissues (Anderson \& Strong 1988; Dolea \& AbouZahr 2003; Tunde-Byass \& Hannah 2003). In fact, the relatively high likelihood of head entrapment, necessitating complex and sometimes risky obstetrical manoeuvres or surgical intervention to free the fetus, has prompted many modern medical practitioners to opt for planned Caesarean sections rather than vaginal deliveries of breech infants (Anderson \& Strong 1988; Hannah et al. 2000; Tunde-Byass \& Hannah 2003). While this approach has not gone unchallenged (e.g. see Kotaska 2004), it emphasises the perceived, if not actual, risks associated with breech births even today.

Given the relative positions and developmental stages of the grave R11 twins, as well as the fact that the breech infant was not (or could not be) removed from its mother's body before burial, it seems almost certain that labour was obstructed, whether by interlocked twins, head entrapment or another condition, such as extended or nuchal arms (where the infant's arms are beside or behind its head) (Tunde-Byass \& Hannah 2003). It is impossible to speculate on the condition of the mother-whether her health, young age and/or previous experience of childbirth (or lack of) might have contributed to the difficult and ultimately unsuccessful birth — or on the effectiveness of those who may have assisted her during labour. Regardless, without the skills, experience and technology of modern medical practitioners, this case of dystocia would have been a virtual death sentence for all three individuals, obstructed labour accounting for as many as 70 per cent of maternal deaths worldwide even in the late twentieth century (WHO 1994). Cause of death for the mother would probably have been infection, haemorrhage (e.g. from uterine rupture) or exhaustion, while that of the infants would most likely have been asphyxia (Neilson et al. 2003).

Grave R11 easily represents one of the oldest examples of dystocic childbirth documented in the archaeological literature. One case from the Mesolithic Swedish cemetery of Skateholm (Persson \& Persson 1984) may be similar in antiquity, but the vast majority of other studies reported are considerably more recent, generally within the last 4000 years (e.g. Sjovold et al. 1974; Hawkes \& Wells 1975; Wells 1978; Owsley \& Bradtmiller 1983; Högberg et al. 1987; Malgosa et al. 2004; Rascón Pérez et al. 2007; Cruz \& Codinha 2010; Willis \&

(C) Antiquity Publications Ltd, 2015 
Oxenham 2013). Interestingly, this case is not unique to the middle Holocene Cis-Baikal, but it is, by far, the oldest. A young adult female (burial 40.1) from the more recent Late Neolithic-Early Bronze Age cemetery of Ust'-Ida I, located on the Angara River about $150 \mathrm{~km}$ north of Lokomotiv, was also recovered with the remains of a near-term fetus, albeit a single one, in utero. The maternal skeleton was directly radiocarbon dated to 4070-3945 cal BP (TO-10347: 3650士60 BP; Weber et al. 2006), making the Ust'-Ida I case about 3700 years more recent than the Lokomotiv one.

\section{Conclusion}

The grave R11 remains from Lokomotiv represent one of the earliest archaeologically documented cases of death during childbirth, as well as the oldest confirmed evidence of human twins worldwide. This latter distinction is particularly relevant given that the occurrence of ancient twins is virtually impossible to establish unequivocally, with most cases discussed in the literature reflecting possible or probable twin status inferred from circumstantial evidence. This case adds to the small but growing body of literature on maternal and perinatal death in the past, and the occurrences of, and risks associated with, human twinning in antiquity.

\section{Acknowledgements}

This research was carried out as part of the Baikal-Hokkaido Archaeology Project (BHAP) based at the University of Alberta (Edmonton, Canada) and funded largely by the Social Sciences and Humanities Research Council (SSHRC) of Canada. We are grateful to Siân Halcrow and an anonymous reviewer for their helpful comments on an earlier version of this paper.

\section{References}

AlberT, A.M. \& W.R. MAPLES. 1995. Stages of epiphyseal union for thoracic and lumbar vertebral centra as a method of age determination for teenage and young adult skeletons. Journal of Forensic Sciences 40: 623-33.

Anderson, G. \& C. STRONG. 1988. The premature breech: caesarean section or trial of labour? Journal of Medical Ethics 14: 18-24.

http://dx.doi.org/10.1136/jme.14.1.18

Arriaza, B., M. Allison \& E. Gerszten. 1988. Maternal mortality in pre-Columbian Indians of Arica, Chile. American Journal of Physical Anthropology 77: 35-41. http://dx.doi.org/10.1002/ajpa.1330770107

BALl, H.L. \& C.M. HiLl. 1996. Reevaluating 'twin infanticide’. Current Anthropology 37: 856-63. http://dx.doi.org/10.1086/204569
BAZALIISKII, V.I. 2010. Mesolithic and Neolithic mortuary complexes in the Baikal region, in A.W. Weber, M.A. Katzenberg \& T.G. Schurr (ed.) Prehistoric hunter-gatherers of the Baikal region, Siberia: bioarchaeological studies of past life ways: 51-86. Philadelphia (PA): University of Pennsylvania Press.

BAZALIISKIY [BAZAliISKII], V.I. \& N.A. SAVELYEV. 2003. The wolf of Baikal: the 'Lokomotiv' Early Neolithic cemetery in Siberia (Russia). Antiquity 77: 20-30.

BLACK, G.A. 1967. Angel site: an archaeological, historical, and ethnological study. Indianapolis: Indiana Historical Society

Blickstein, I. \& R.B. KALISH. 2003. Birthweight discordance in multiple pregnancy. Twin Research 6: 526-31. http://dx.doi.org/10.1375/ 136905203322686536

Boggess, K.A. \& C.A. Chisholm. 1997. Delivery of the nonvertex second twin: a review of the literature. Obstetrical and Gynecological Survey 52: 728-35. http://dx.doi.org/10.1097/ 00006254-199712000-00003 
BORAH, T. \& A. DAS. 2012. Locked twins: a rarity. Annals of Medical and Health Science Research 2: 204-205. http://dx.doi.org/10.4103/21419248.105676

BOWMAN, P.R. 1983. Obstructed labour due to locked twins. Irish Journal of Medical Science 152: 134-35. http://dx.doi.org/10.1007/BF02960053

BreathNaCh, F.M., F.M. McAulifFe, M. Geary, S. Daly, J.R. Higgins, J. DORnAN, J.J. MORRISON, G. Burke, S. Higgins, P. Dicker, F. Manning, R. Mahony \& F.D. Malone. 2011. Definition of inter-twin birth weight discordance. Obstetrics and Gynecology 118: 94-103. http://dx.doi.org/ 10.1097/AOG.0b013e31821fd208

Buikstra, J.E. \& D.H. UBELAKER. 1994. Standards for data collection from human skeletal remains: proceedings of a seminar at the Field Museum of Natural History, organized by Jonathan Haas (Arkansas Archaeological Survey Research Series 44). Fayetteville: University of Arkansas.

Carroll, M.A. \& E.R. Yeomans. 2006. Vaginal delivery of twins. Clinical Obstetrics and Gynecology 49: 154-66. http://dx.doi.org/10.1097/ 01.grf.0000197541.42067.9b

Chamberlain, G. 2001. Two babies that could have changed world history. Historian 72: 6-10

Chauhan, S.P., J.A. Scardo, E. Hayes, A.Z. Abuhamad \& V. Berghella. 2010. Twins: prevalence, problems, and preterm births. American Journal of Obstetrics and Gynecology 203: 305-15. http://dx.doi.org/10.1016/j.ajog.2010.04.031

Chervenak, F.A., R.E. Johnson, S. Youcha, J.L. HobBIns \& R.L. BERKOWITZ. 1985. Intrapartum management of twin gestation. Obstetrics and Gynecology 65: 119-24.

Cohen, M., S.G. KoHL \& A.H. Rosenthal. 1965. Fetal interlocking complicating twin gestation. American Journal of Obstetrics and Gynecology 91: 407-12.

Crespo, L., M.E. SubirÀ \& J. RuIZ. 2011. Twins in prehistory: the case from Olèrdola (Barcelona, Spain; s. IV II BC). International Journal of Osteoarchaeology 21: 751-56. http://dx.doi.org/10.1002/oa.1169

Cruz, C.B. \& S. Codinha. 2010. Death of mother and child due to dystocia in $19^{\text {th }}$ century Portugal. International Journal of Osteoarchaeology 20: 491-96. http://dx.doi.org/10.1002/oa.1069

DeVeciana, M., C. Major \& M.A. Morgan. 1995. Labor and delivery management of the multiple gestation. Obstetrics and Gynecology Clinics of North America 22: 235-46.

Dolea, C. \& C. AbouZahr. 2003. Global burden of obstructed labour in the year 2000. Available at: http://www.who.int/healthinfo/statistics/ bod_obstructedlabour.pdf (accessed 28 July 2014).
EinWÖGerer, T., H. Friesinger, M. HÄNdel, C. Neugebauer-Maresch, U. Simon \& M.

Teschler-Nicola. 2006. Upper Paleolithic infant burials. Nature 444: 285.

http://dx.doi.org/10.1038/444285a

FAZEKAS, I.G. \& F. KÓSA. 1978. Forensic fetal osteology. Budapest: Akadémiai Kiadó.

FLOHR, S. 2014. Twin burials in prehistory: a possible case from the Iron Age of Germany. International Journal of Osteoarchaeology 24: 116-22. http://dx.doi.org/10.1002/oa.2236

GHai, V. \& D. Vidyasagar. 1988. Morbidity and mortality factors in twins: an epidemiologic approach. Clinics in Perinatology 15: 123-40.

GORDON, R. 1956. Interlocked twins: a case report and brief review of the literature. South African Medical Journal 30: 661-63.

GuY, H., C. Masset \& C. BAud. 1997. Infant taphonomy. International Journal of Osteoarchaeology 7: 221-29. http://dx.doi.org/ 10.1002/(SICI) 1099-1212(199705)7:3<221::AID$\mathrm{OA} 338>3.0 . \mathrm{CO} ; 2-\mathrm{Z}$

Halcrow, S., N. Tayles, R. Inglis \& C. Higham. 2012. Newborn twins from prehistoric mainland Southeast Asia: birth, death, and personhood. Antiquity 86: 838-52.

Hannah, M.E., W.J. Hannah, S.A. Hewson, E.D. HodnetT, S. SAigal \& A.R. Willan. 2000. Planned Cesarean section versus planned vaginal birth for breech presentation at term: a randomized multicentre trial. The Lancet 356: 1375-83. http://dx.doi.org/10.1016/S0140-6736(00)02840-3

HaWASS, Z. \& S.N. SAlEEM. 2011. Mummified daughters of King Tutankhamun: archeologic and CT studies. American Journal of Roentgenology 197: 29-36. http://dx.doi.org/10.2214/AJR.11.6837

HaWkes, S.C. \& C. Wells. 1975. An Anglo-Saxon obstetric calamity from Kingsworthy, Hampshire. Medical and Biological Illustration 25(1): 47-51.

Högberg, U., E. Iregren, C.-H. Siven \& L. Diener. 1987. Maternal deaths in medieval Sweden: an osteological and life table analysis. Journal of Biosocial Science 19: 495-503. http://dx.doi.org/10.1017/S0021932000017120

KAHUNDA, S. 1972. Locked twins. Obstetrics and Gynecology 39: 453-59.

Kimball, A.P. \& P.R. Rand. 1950. Manoeuvre for the simultaneous delivery of chin to chin locked twins. American Journal of Obstetrics and Gynecology 59: 1167.

KOTASKA, A. 2004. The inappropriate use of randomised trials to evaluate complex phenomena: a case study of vaginal breech delivery. British Medical Journal 329: 1039. http://dx.doi.org/ 10.1136/bmj.329.7473.1039

(C) Antiquity Publications Ltd, 2015 
KurZEL, R.B. 1998. Twin entanglement revisited. Twin Research 1: 138-41. http://dx.doi.org/ 10.1375/twin.1.3.138

LAROS, R.K. \& B.J. DATTEL. 1998. Management of twin pregnancy: the vaginal route is still safe. American Journal of Obstetrics and Gynecology 158: 1330-38. http://dx.doi.org/10.1016/ 0002-9378(88)90364-X

Lasso, E., M. Santos, A. Rico, J.V. Pachar \& J. LUCENA. 2009. Expulsión fetal postmortem [Postmortem fetal extrusion]. Cuadernos de Medicina Forense 15: 77-81.

Luke, B., F.R. Wittler, H. Abbey, T. Feng, A.B. Namnoum, D.M. Paige \& T.R. Johnson. 1991. Gestational age-specific birthweights of twins versus singletons. Acta Genetic Medi Gemellology (Roma) 40(1): 69-76.

Malgosa, A., A. Alesan, S. Safont, M. Ballbé \& M.M. AyalA. 2004. A dystocic childbirth in the Spanish Bronze Age. International Journal of Osteoarchaeology 14: 98-103. http://dx.doi.org/10.1002/oa.714

Marshall, C., P.A. Tench, D.C. CoOK \& F.A. KAEstle. 2011. Conjoined twins at Angel Mounds? An ancient DNA perspective. American Journal of Physical Anthropology 46: 138-42. http://dx.doi.org/10.1002/ajpa.21557

MeIndL, R.S. \& C.O. LovejOY. 1989. Age changes in the pelvis: implications for paleodemography, in M.Y. Işcan (ed.) Age markers in the human skeleton: 137-68. Springfield (IL): Charles C. Thomas.

Miller, J., S.P. Chauhan \& A.Z. Abuhamad. 2012. Discordant twins: diagnosis, evaluation, and management. American Journal of Obstetrics and Gynecology 206: 10-20. http://dx.doi.org/10.1016/j.ajog.2011.06.075

Moorrees, C., E. Fanning \& E. Hunt. 1963. Age variation of formation stages for ten permanent teeth. Dental Research 42: 1490-502. http://dx.doi.org/10.1177/00220345630420062701

Nassar, A.H., H.H. MaArouf, E.M. Hobeika, H.M. ABD EsSAMAD \& I.M. USTA. 2004. Breech presenting twin A: is vaginal delivery safe? Journal of Perinatal Medicine 32: 470-74. http://dx.doi.org/10.1515/JPM.2004.129

NeIlson, J.P.O., T. LaVEnder, S. Quenby \& S. Wray. 2003. Obstructed labour. British Medical Bulletin 67: 191-204. http://dx.doi.org/10.1093/ $\mathrm{bmb} / \mathrm{ldg} 018$

Nissen, E.D. 1958. Twins: collision, impaction, compaction, and interlocking. Obstetrics and Gynecology 11: 514-26.
Owsley, D.W. \& B. BradtMiller. 1983. Mortality of pregnant females in Arikara villages: osteological evidence. American Journal of Physical Anthropology 61: 331-36. http://dx.doi.org/10.1002/ajpa. 1330610307

Persson, O. \& E. Persson. 1984. Anthropological report on the Mesolithic graves from Skateholm, southern Sweden. I: excavation seasons 1980-82. Lund: Institute of Archaeology, University of Lund.

Pounder, D., M. Prokopec \& G. Pretty. 1983. A probable case of euthanasia amongst prehistoric Aborigines at Roonka, South Australia. Forensic Science International 23: 99-108. http://dx.doi.org/10.1016/0379-0738(83)90138-X

Powell, T. \& A. Brodie. 1963. Closure of the spheno-occipital synchondrosis. Anatomical Record 147: 15-23. http://dx.doi.org/10.1002/ ar. 1091470104

Rascón Pérez, J., O. Cambra-Moo \& A. GonzÁlez MARTín. 2007. A multidisciplinary approach reveals an extraordinary double inhumation in the osteoarchaeological record. Journal of Taphonomy 5: 91-101.

Robertson, P.A., C.M. Foran, M.S. Croughan-Minihane \& S.J. Kilpatrick. 1995. Head entrapment and neonatal outcome by mode of delivery in breech deliveries from twenty-four to twenty-seven weeks of gestation. American Journal of Obstetrics and Gynecology 173: 1171-76. http://dx.doi.org/10.1016/0002-9378(95)91347-5

Rydhstrom, H. \& G. Cullberg. 1990. Pregnancies with growth-retarded twins in breech-vertex presentation at increased risk for entanglement during delivery. Journal of Perinatal Medicine 18: 45-50. http://dx.doi.org/10.1515/ jpme.1990.18.1.45

SCHAEFER, M., S. BLACK \& L. SCHEUER. 2009. Juvenile osteology: a laboratory and field manual. New York: Academic Press.

Scheuer, L. \& S. MacLaughlin-Black. 1994. Age estimation from the pars basilaris of the fetal and juvenile occipital bone. International Journal of Osteoarchaeology 4: 377-80. http://dx.doi.org/10.1002/oa.1390040412

Schulz, F., K. PÚsChel \& M. TsOKOS. 2005. Postmortem fetal extrusion in a case of maternal heroin intoxication. Forensic Science Medicine and Pathology 1: 273-76. http://dx.doi.org/10.1385/FSMP:1:4:273

Sjovold, T., I. Swedborg \& I. Diener. 1974. A pregnant woman from the Middle Ages with exostosis multiplex. Ossa 1: 3-23. 


\section{Death by twins}

SLAus, M. 2000. Biocultural analysis of sex differences in mortality profiles and stress levels in the late medieval population from Nova Raca, Croatia. American Journal of Physical Anthropology 111: 193-209. http://dx.doi.org/10.1002/(SICI)10968644(200002)111:2<193::AID-AJPA6>3.0.CO; 2-0

SMITH, B.H. 1984. Patterns of molar wear in hunter-gatherers and agriculturalists. American Journal of Physical Anthropology 63: 39-56. http://dx.doi.org/10.1002/ajpa.1330630107

Tough, S.C., C.A. Green, L.W. Svenson \& J. Belik. 2000. Effects of in vitro fertilization on low weight, preterm delivery, and multiple births. Journal of Pediatrics 136: 618-22. http://dx.doi.org/ $10.1067 / \mathrm{mpd} .2000 .105132$

Tunde-Byass, M.O. \& M.E. HannaH. 2003. Breech vaginal delivery at or near term. Seminars in Perinatology 27: 34-45. http://dx.doi.org/ 10.1053/sper.2003.50003

VAN EYK, E.A. \& H.J. HuIsJES. 1983. Neonatal mortality and morbidity associated with preterm breech presentation. European Journal of Obstetrics \& Gynaecology and Reproductive Biology 15: 17-23. http://dx.doi.org/10.1016/0028-2243(83)90292-7

WebB, P.A.O. \& J.M. SuCHEY. 1985. Epiphyseal union of the anterior iliac crest and medial clavicle in a modern sample of American males and females. American Journal of Physical Anthropology 68: 457-66. http://dx.doi.org/10.1002/ ajpa. 1330680402
Weber, A.W., D.W. Link \& M.A. KatZenberG. 2002. Hunter-gatherer culture change and continuity in the middle Holocene of the Cis-Baikal, Siberia. Journal of Anthropological Archaeology 21: 230-99. http://dx.doi.org/10.1006/jaar.2001.0395

Weber, A.W., R.P. Beukens, V.I. BAZALIISKiI, O.I. GoriunOVA \& N.A. SAVEL'EV. 2006. Radiocarbon dates from Neolithic and Bronze Age cemeteries in the Cis-Baikal region of Siberia. Radiocarbon 48: $1-40$.

Weber, A.W., D. White, V.I. BaZalisski, O.I. Goriunova, N.A. SAVEL'EV \& M.A. KatZENBERG. 2011. Hunter-gatherer foraging ranges, migrations, and travel in the middle Holocene Baikal region of Siberia: insights from carbon and nitrogen stable isotope signatures. Journal of Anthropological Archaeology 30: 523-48. http://dx.doi.org/10.1016/j.jaa.2011.06.006

Wells, C. 1978. A medieval burial of a pregnant woman. The Practitioner 221: 442-44.

WHO World Health Organization Maternal Health and Safe Motherhood Programme. 1994. World Health Organization partograph in management of labour. The Lancet 343: 1399-404.

Willis, A. \& M.F. OxEnHAM. 2013. A case of maternal and perinatal death in Neolithic southern Vietnam, c. 2100-1050 BCE. International Journal of Osteoarchaeology 23: 676-84. http://dx.doi.org/10.1002/oa.1296

Received: 2 January 2014; Accepted: 27 March 2014; Revised: 29 April 2014

C) Antiquity Publications Ltd, 2015 